\title{
Investigation of the Susceptibility of the WE54 Magnesium-Based Alloy to Stress Corrosion Cracking
}

\author{
Maria Sozańska (D) and Adrian Mościcki
}

\author{
(Submitted November 20, 2018; in revised form October 31, 2019; published online January 29, 2020)
}

\begin{abstract}
This article presents an assessment of the susceptibility of the WE54 magnesium-based alloy to stress corrosion cracking in an $0.1 \mathrm{M} \mathrm{Na}_{2} \mathrm{SO}_{4}$ environment. In this work, the basis criterion for assessing the alloy's behavior under complex mechanical and corrosive loads is the deterioration in its mechanical properties (elongation $-\varepsilon, \%$, reduction in area $-Z, \%$, tensile strength $-R_{m}, M P a$ ) along with a fractographic analysis of fracture surfaces. The WE54 magnesium-based alloy was subjected to the slow strain rate test (SSRT) under mechanical loads in corrosive environment (0.1 $\mathrm{M} \mathrm{Na}_{2} \mathrm{SO}_{4}$ solution). The test was carried out in four variants: (a) SSRT in air, (b) cathodic hydrogen charging for $24 \mathrm{~h}$ at a current density of $50 \mathrm{~mA} / \mathrm{cm}^{2}$ followed by SSRT in air, (c) SSRT in a corrosive environment under open-circuit potential conditions, and (d) SSRT in a corrosive environment under cathodic polarization at a current density of $50 \mathrm{~mA} / \mathrm{cm}^{2}$. In each variant, the content of hydrogen in the alloy was determined. It was demonstrated that under SCC conditions, in the presence of hydrogen, the plastic properties of WE54 decreased significantly, whereas the alloy's strength properties changed to a smaller degree. The change in the mechanical properties under SCC conditions in a corrosive environment was accompanied by a change in the fracture surface morphology and by the presence of numerous cracks, both on fracture surfaces and in the alloy's microstructure.
\end{abstract}

Keywords fractographic analysis, hydrogen, magnesium alloy, SCC, WE54

\section{Introduction}

Magnesium and its alloys, with their low density and a good set of technological properties (workability, castability, machinability, and full recyclability) and mechanical properties (considerable specific stiffness and specific strength), are a very attractive construction material in those industries where it is important to reduce the mass of a construction and at the same time retain its mechanical properties (Ref 1,2$)$. The main examples are the motor and aerospace industries, where magnesium-based alloys are used for manufacturing various components, such as engine parts, transmission cases, pumps, oil sumps, and steering wheels (Ref 3-6). In the recent years, there has been a steady tendency to use increasingly strong magnesium-based alloys for manufacturing components that often work at elevated temperatures (above $150{ }^{\circ} \mathrm{C}$ ) and in a corrosive environment. Attempts at improving the mechanical properties (e.g., creep resistance) of magnesium-based alloys involve reductions in the content of aluminum (in alloys from the Mg-Al group, such as AZ91, AM50, and AM60) and the introduction of such alloying agents as calcium, silicon, strontium, and rare earth (RE) elements. It is known that the

Maria Sozańska, Faculty of Materials Engineering, Silesian University of Technology, Krasińskiego 8, 40-019 Katowice, Poland; and Adrian Mościcki, BGH Polska Sp. z o.o., Żelazna 9, 40-851 Katowice, Poland. Contact e-mails: maria.sozanska@polsl.pl and adrian.moscicki@bgh.pl. thermodynamically stable intermetallic phases that form at grain boundaries during solidification $\left(\mathrm{Al}_{4} \mathrm{RE}\right.$ or $\mathrm{Al}_{11}(\mathrm{RE})_{3}$, $\mathrm{Al}_{2} \mathrm{RE}$, and $\mathrm{Mg}_{17} \mathrm{Al}_{12}$ ) enhance creep resistance; however, their effect on stress corrosion cracking is not clearly known.

In general, magnesium-based alloys have poor corrosion resistance, even in dilute electrolyte solutions and in water (Ref 6). Structural components made of magnesium-based alloys are often subject not only to mechanical loads, but also to the action of a corrosive environment. In such service conditions, a particularly dangerous phenomenon is stress corrosion cracking (SCC). Damage and malfunctions resulting from stress corrosion cracking during the service life are usually sudden and often have catastrophic effects. This is because SCC usually takes place under the conditions of minor general corrosion, and in the absence of visible corrosion deposits - at first, cracks are very narrow and hardly noticeable, and thus it is difficult to eliminate them. The initiation and growth of a microcrack under stress corrosion cracking conditions are very difficult to detect, although they lead to major changes in the microstructure and the properties of the material (Ref 7). A particularly dangerous factor that affects stress corrosion cracking is the presence of hydrogen in the environment, which leads to a special type of material degradation referred to as "hydrogenassisted stress corrosion cracking." In the most extreme cases, a very low concentration of hydrogen in the material $-1 \mathrm{ppm}$ - may lead to its plasticity being reduced by up to $90 \%$ (Ref 6).

Literature data (Ref 8,9) concerning stress corrosion cracking suggest that the phenomenon may be caused by stresses that are below $50 \%$ of the yield strength of particular magnesium-based alloy being in service, in environments causing only negligible corrosion in those alloys (Ref 9-11). Hydrogen-assisted stress corrosion cracking is particularly dangerous for the group of high-strength magnesium-based alloys containing rare earth elements. Literature data concern- 
ing susceptibility to SCC in hydrogen-containing environments are very scarce for alloys containing rare earth elements (e.g., Mg-Y-RE) and intended to be used at elevated temperatures. The literature presents many test results concerning stress corrosion cracking in $\mathrm{Mg}-\mathrm{Al}-\mathrm{Zn}$ alloys and rather few test results concerning $\mathrm{Mg}-\mathrm{Zn}-\mathrm{RE}-\mathrm{Zr}$ and $\mathrm{Mg}-\mathrm{Ag}-\mathrm{RE}-\mathrm{Zr}$ alloys. There are limited data concerning hydrogen damage and stress corrosion cracking in high-strength alloys from the Mg-Y-RE$\mathrm{Zr}$ and $\mathrm{Mg}$-Al-RE groups.

Stress corrosion cracking processes can be analyzed using various criteria and research techniques, including mechanical tests, electrochemical methods, and examinations of the microstructure and fracture surfaces. The most frequently used test is the slow strain rate test-SSRT (Ref 6, 11, 12). During the test, the material, most often in the form of circular or rectangular samples, is subjected to increasing strain in a given hydrogencontaining environment. The strain may be stopped at any time, e.g., right after the initiation of the first microcracks in the microstructure. However, much more often, it is continued until the complete fracture of the specimen (Ref 13). The test provides a stress-elongation curve along with the quantitative data that can be read from it. During the performance of an SSRT test, it is very important to select the right strain rate so that it is possible to observe the influence of the environment on the material tested.

In this study, it is attempted to analyze stress corrosion cracking in a modern magnesium-based alloy containing rare earth elements - WE54 - intended for use at temperatures of up to $300{ }^{\circ} \mathrm{C}$. WE54 is a Mg-Y-RE-Zr alloy. The RE mixture in the WE54 alloy contains neodymium, gadolinium, ytterbium, erbium, and dysprosium. It is believed that precipitates with enriched with rare earth metals may affect not only creep resistance, but also stress corrosion cracking resistance. The susceptibility of WE54 to stress corrosion cracking was assessed by determining the changes in its mechanical properties under an SSRT test in an $0.1 \mathrm{M} \mathrm{Na}_{2} \mathrm{SO}_{4}$ solution. The mechanical tests were complemented by an analysis of the alloy's microstructure and the changes in the morphology of the fracture surfaces being the result of stress corrosion cracking.

\section{Test Material and Test Methodology}

The test material was the WE54 magnesium-based alloy containing rare earth elements (wt.\%: $4.8 \div 5.5 \mathrm{Y}$, min. $0.4 \mathrm{Zr}$, $2.5 \div 4.0 \mathrm{RE}, \mathrm{Mg}$ - balance). The alloy was obtained by extrusion in the form of 1000-mm-long rods having a diameter of $25 \mathrm{~mm}$.

\subsection{Slow Strain Rate Test (SSRT)}

The slow strain rate test (SSRT) was carried out in accordance with ASTM G129-00 (2013) (Ref 29) — the tests were carried out on a Zwick Kappa 50DS testing machine, and the samples were made in accordance with the standard PN-EN ISO 7539-4 (Ref 30). The alloys to be tested were formed into cylindrical specimens with a gauge length of $20 \mathrm{~mm}$ and a diameter of $5 \mathrm{~mm}$. The specimens obtained were cleaned with acetone and then subjected to the slow strain rate test in four variants:

- $\quad$ SSRT in air (variant I),

- hydrogen charging in a corrosive environment, under cathodic polarization, for $24 \mathrm{~h}$, at a current density of $50 \mathrm{~mA} / \mathrm{cm}^{2}$, followed by SSRT in air (variant II),
- SSRT in a corrosive environment under open-circuit potential conditions (variant III),

- SSRT in a corrosive environment under cathodic polarization at a current density of $50 \mathrm{~mA} / \mathrm{cm}^{2}$ (variant IV).

Each of the SSRT variants was carried out at ambient temperature, at the same strain rate of $=9 \cdot 10^{-7} \mathrm{~s}^{-1}$. The corrosive environment was $0.1 \mathrm{M} \mathrm{Na}_{2} \mathrm{SO}_{4}$ solution. Each variant was applied to two specimens. The following parameters were obtained in the tests:

- elongation at fracture- $-\varepsilon, \%$

- reduction in area at fracture-Z, $\%$

- tensile strength- $\mathrm{R}_{\mathrm{m}}, \mathrm{MPa}$

- time to fracture - $t, h$

\subsection{Fractographic Examinations}

The materials to be examined were the fracture surfaces obtained as a result of the SSRT tests. The specimens were cleaned so that the corrosion products that formed on some fracture surfaces would not hinder the examination. For this purpose, they were cleaned in $\mathrm{CrO}_{3}+10 \mathrm{~g} / \mathrm{l} \mathrm{AgNO}_{3}$ solution $(200 \mathrm{~g} / \mathrm{l})$ for $1 \div 3$ min (as necessary). The specimens were then cleaned three times in an ultrasonic washer with the use of acetone, each time using new acetone. The fracture surfaces were analyzed using a Hitachi S-3400 N scanning electron microscope.

Fracture profiles were obtained by grinding one of the fracture surfaces with SiC abrasive papers with a grit size of up to 1200 . The profiles were then polished using Struers diamond suspensions with a particle size of up to $1 \mu \mathrm{m}$. The last stage was the final polishing using $0.05 \mu \mathrm{m} \mathrm{Al} \mathrm{O}_{3}$ suspension. Due to the high susceptibility of magnesium-based alloys to corrosion in water environments, the time between the polishing and drying was as short as possible and did not exceed $10 \mathrm{~s}$.

\subsection{Hydrogen Charging and Assessment of Hydrogen Content}

The test specimens were subjected to cathodic hydrogen charging in an $0.1 \mathrm{M} \mathrm{Na}_{2} \mathrm{SO}_{4}$ aqueous solution and in a $0.1 \mathrm{M}$ $\mathrm{Na}_{2} \mathrm{SO}_{4}$ solution with the addition of $\mathrm{As}_{2} \mathrm{O}_{3}(5 \mathrm{mg} / \mathrm{l})$. The current density was $50 \mathrm{~mA} / \mathrm{cm}^{2}$, and the hydrogen charging time was $24 \mathrm{~h}$.

The hydrogen concentration in the specimens was analyzed using a LECO TCHEN600 elemental analyzer. Hydrogen concentration was analyzed for the specimens:

- in their initial condition (prior to the hydrogen charging process),

- directly after the hydrogen charging process,

- after the SSRT tests.

\section{Test Results}

\subsection{Microstructure of the WE54 Alloy in Initial State}

In the initial condition, precipitates of intermetallic phases of various shapes and diameters not exceeding $10 \mu \mathrm{m}$ were identified in the microstructure of WE54 (Fig. 1). The precip- 

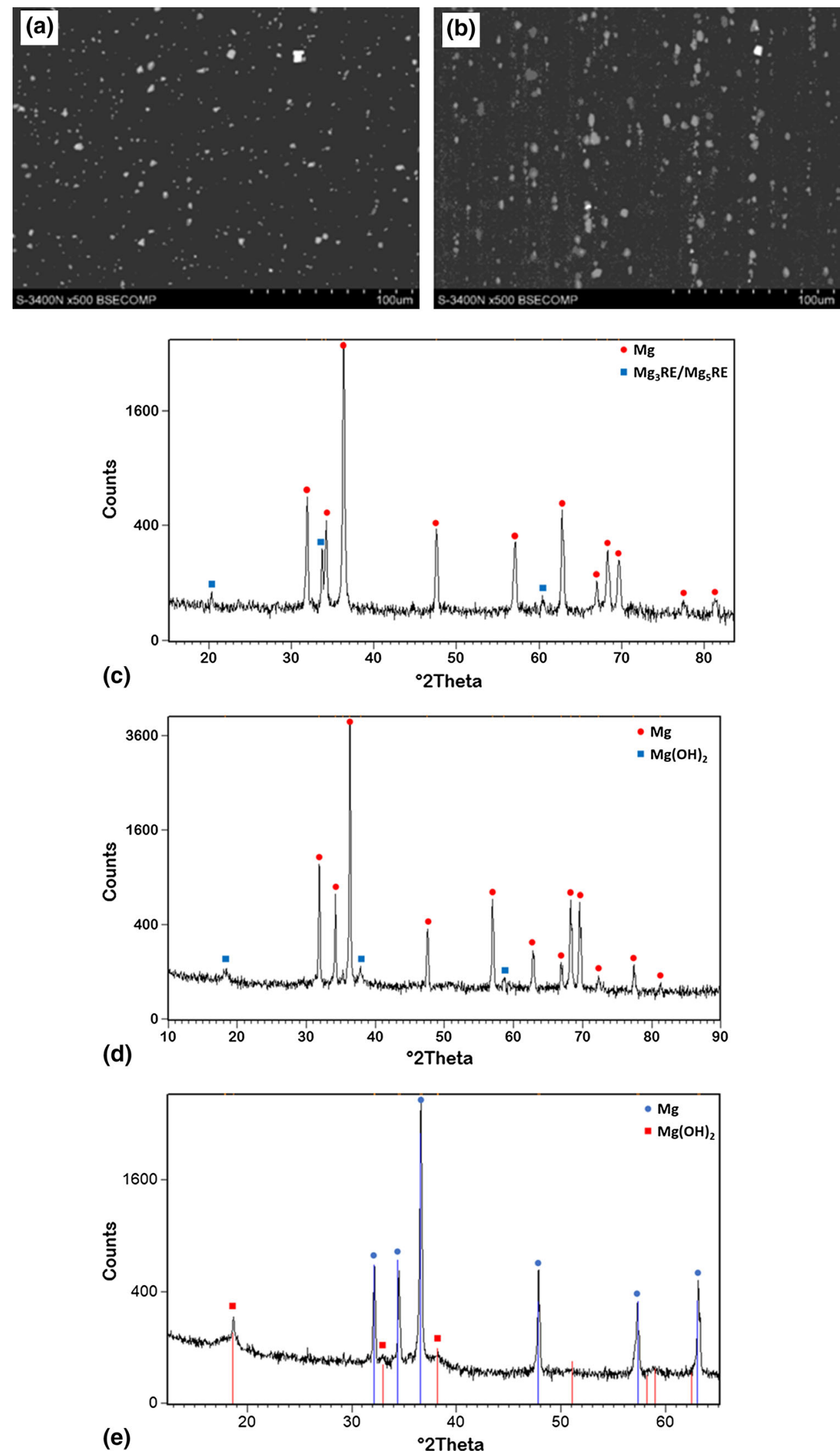

Fig. 1 Microstructure of WE54 in the initial condition: (a) section perpendicular to the extrusion direction; (b) section parallel to the extrusion direction; (c) x-ray diffraction pattern of WE54 alloy in initial state; (d) x-ray diffraction pattern of WE54 alloy after 7 days of exposure to $0.1 \mathrm{M} \mathrm{Na}_{2} \mathrm{SO}_{4}$ solution in open-circuit conditions; (e) x-ray diffraction pattern of WE54 alloy) after $24 \mathrm{~h}$ of exposure to $0.1 \mathrm{M} \mathrm{Na}_{2} \mathrm{SO}_{4}$ solution under cathodic polarization conditions 
itates on the section perpendicular to the extrusion direction were distributed evenly (Fig. 1a). On the section parallel to the extrusion direction, the characteristic clustering of precipitates into bands corresponding to the extrusion direction was observed (Fig. 1b).

Because SSC tests were carried out in a corrosive environment, the subject of the tests was the phase composition of the WE54 alloy in the delivery condition (Fig. 1c) and after exposure in the analyzed corrosive environments (Fig. 1d and e).

\subsection{SSRT Tests on WE54}

The stress-strain curves obtained as a result of the four SSRT variants for the WE54 specimens are shown in Fig. 2. They have a typical shape, with an elastic and plastic strain zone, but with no distinct yield strength. Thus, a yield strength $\mathrm{R}_{0.2}$ was adopted for the specimens tested. Irrespective of the test variant, its value was very similar and was about $200 \mathrm{MPa}$. The highest tensile strength $\left(\mathrm{R}_{\mathrm{m}} \approx 290 \mathrm{MPa}\right)$ was recorded for the specimens strained in air-both those that had not been exposed to the corrosive environment (Fig. 2a) (variant I) and
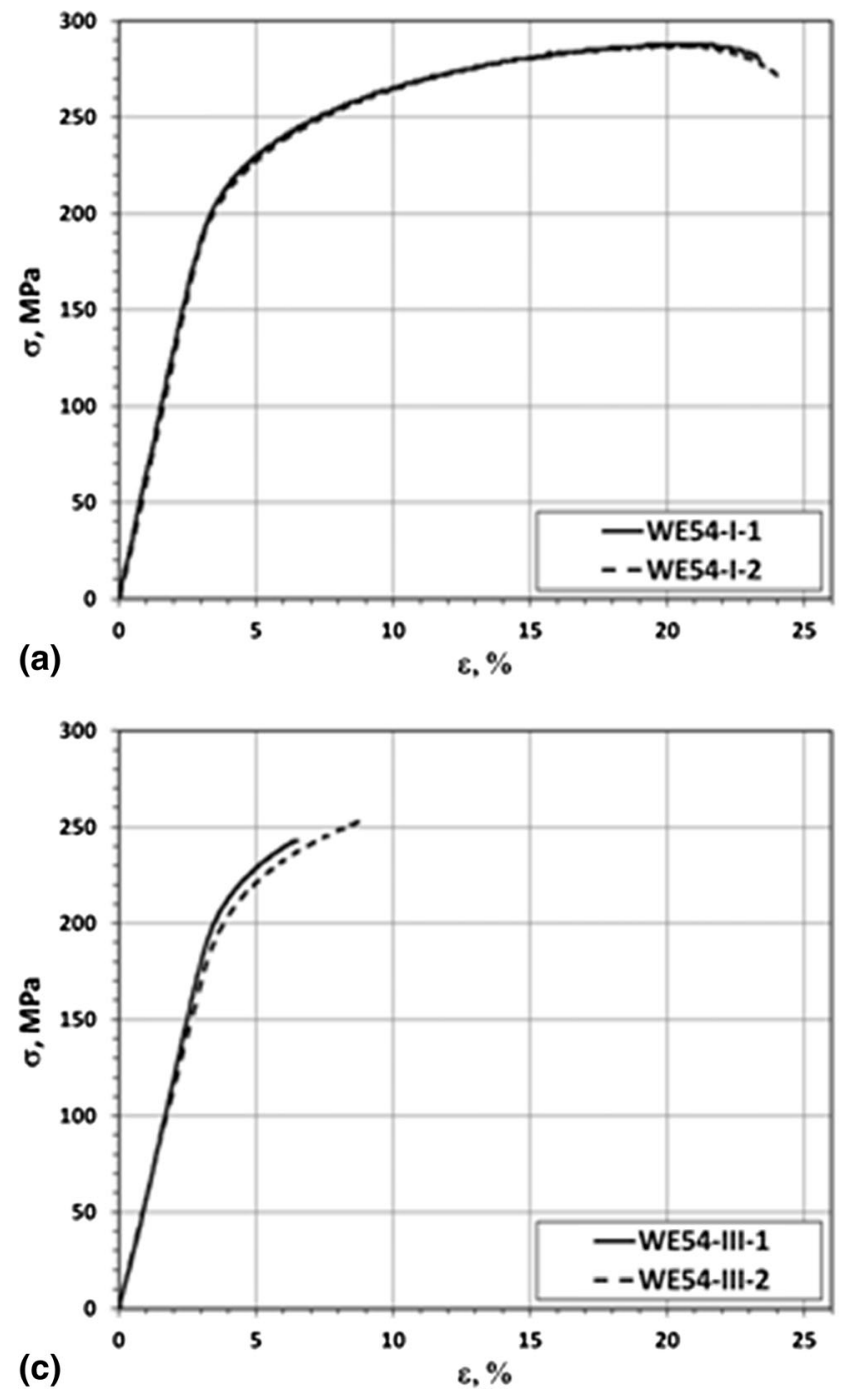

those that had been exposed to the corrosive environment (Fig. 2b) (variant II).

A considerable decrease in strength was observed for the specimens strained during exposure to the corrosive environment. The specimens tested under cathodic polarization had the lowest strength $\left(R_{\mathrm{m}} \approx 230 \mathrm{MPa}\right)$ (Fig. $2 \mathrm{~d}$ ) (variant IV). The strength of the specimens tested at open circuit (Fig. 2c) (variant III) was $R_{\mathrm{m}} \approx 250 \mathrm{MPa}$. The best plasticity was displayed by the specimens tested in air ( $\varepsilon \approx 24 \%, Z \approx 20 \%$ ). A considerable decrease in plasticity was observed for the specimens strained during exposure to the corrosive environment. The values recorded for the specimens tested at open circuit (Fig. 2c) (variant III) were: elongation $\varepsilon=6.5 \div 8.9 \%$ (depending on the specimen) and reduction in area $Z=7.8 \%$. The values recorded for the specimens tested under cathodic polarization (Fig. 1d) (variant IV) were: elongation $\varepsilon=6.0 \%$ and reduction in area $Z=10 \%$. Detailed mechanical property results of the SSRT tests on the WE54 specimens are given in Table 1.

The results of the analysis of the hydrogen concentration in the WE54 specimens after the SSRT tests showed that the
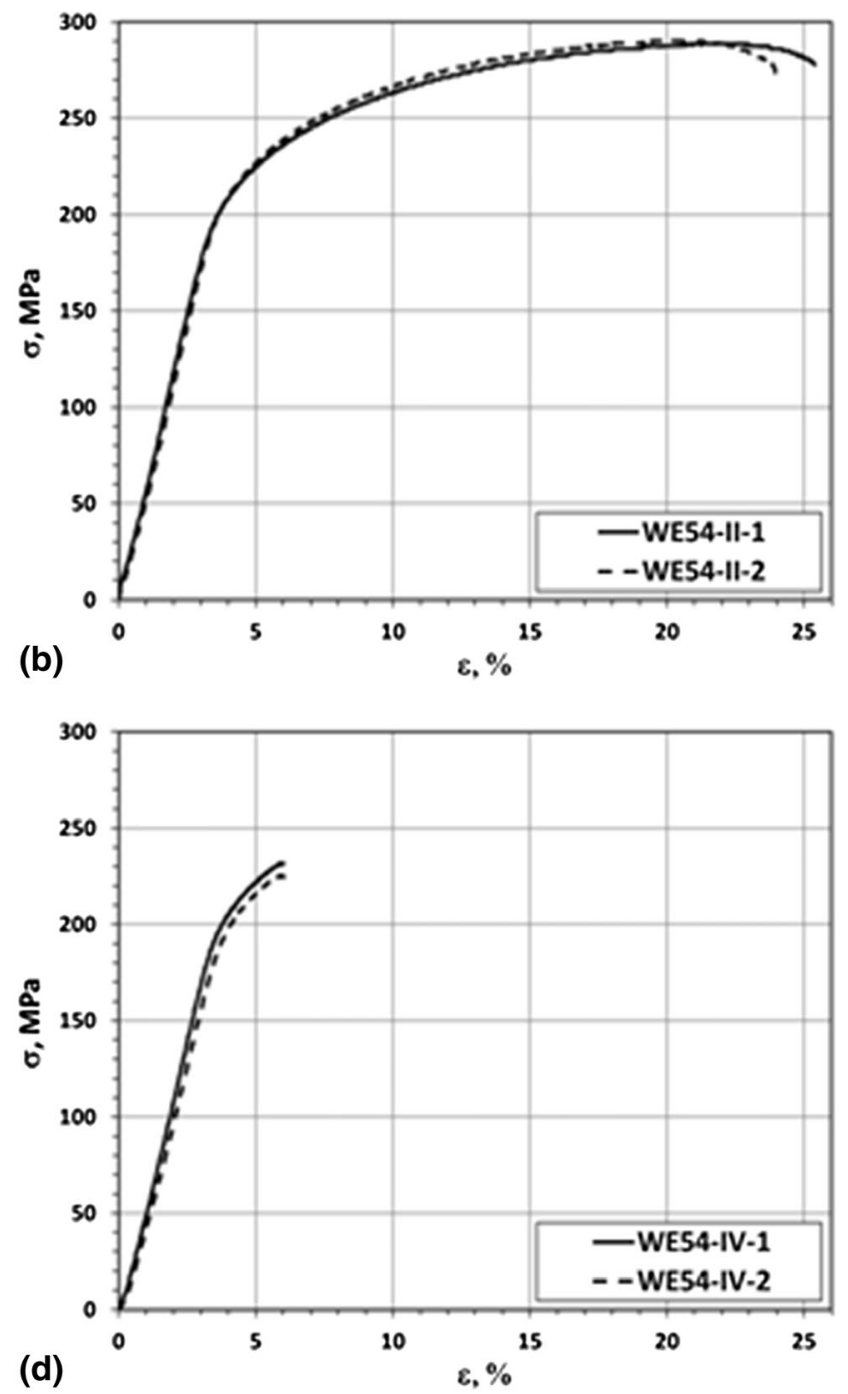

Fig. 2 Stress-strain curves $\left(=9 \cdot 10^{-7} \mathrm{~s}^{-1}\right)$ for WE54 specimens strained (a) in air (variant 1$)$; (b) in air, after $24 \mathrm{~h}$ of exposure to the corrosive environment under cathodic polarization (variant 2); (c) in the corrosive environment, under open-circuit potential conditions (variant 3); (d) in the corrosive environment, under cathodic polarization (variant 4) 
Table 1 Mechanical properties of the WE54 specimens obtained in the different variants of the SSRT test $\left(=9 \cdot 10^{-7} \mathrm{~s}^{-1}\right)$

\begin{tabular}{lcccccc}
\hline Specimen designation & Test variant & $\mathbf{\varepsilon , ~} \%$ & $\boldsymbol{Z , ~} \%$ & $\boldsymbol{R}_{\mathbf{0 , 2}, \mathbf{2}}$ MPa & $\boldsymbol{R}_{\mathbf{m}}, \mathbf{M P a}$ & Time to fracture-t, h \\
\hline WE54-I-1 & 1 & 23.4 & 19.0 & 200 & 288 & 71.1 \\
WE54-I-2 & 1 & 24.2 & 22.6 & 195 & 287 & 73.2 \\
WE54-II-1 & 2 & 25.4 & 17.2 & 201 & 289 & 77.9 \\
WE54-II-2 & 2 & 23.9 & 22.6 & 202 & 290 & 73.6 \\
WE54-III-1 & 3 & 6.5 & 7.8 & 202 & 243 & 28.8 \\
WE54-III-2 & 3 & 8.9 & 7.8 & 196 & 253 & 18.9 \\
WE54-IV-1 & 4 & 6.0 & 11.6 & 198 & 232 & 18.7 \\
WE54-IV-2 & 4 & 6.0 & 9.8 & 196 & 226 & \\
\hline
\end{tabular}

specimens tested in air had the lowest hydrogen concentration $\left(C_{\mathrm{H}}=25.0 \pm 0.0 \mathrm{ppm}\right)$. The highest hydrogen concentration was recorded for the specimens tested under cathodic polarization $\left(C_{\mathrm{H}}=31.7 \pm 0.6 \mathrm{ppm}\right)$ (variant IV) and the specimens tested in air following exposure to the corrosive environment under cathodic polarization $\left(C_{\mathrm{H}}=31.3 \pm 0.6 \mathrm{ppm}\right)$. The specimens tested under open-circuit conditions had a medium hydrogen concentration $\left(C_{\mathrm{H}}=27.3 \pm 0.6 \mathrm{ppm}\right)$ (variant III).

\subsection{Fractographic Examinations of WE54 After the SSRT Tests}

The fracture surfaces obtained as a result of the SSRT tests were subjected to a fractographic analysis aimed at determining the influence of particular environments on the alloy's microstructure and mechanical properties. The analysis covered fracture surfaces, specimen side surfaces, and fracture profiles. This made it possible to examine not only the changes in the microstructure on the surfaces coming into contact with the corrosive environment, but also the depth of those changes.

The WE54 specimens tested in air were characterized by significant plastic deformation in the form of reduction in area (Fig. 3a). After tests in SSC conditions, there is a lack of visible plastic deformation of the samples - changes in sample diameter are very small (Fig. 5a, 7a, and 9a). Numerous microvoids of various sizes were identified on the specimens' side surfaces, however, not larger than $20 \mu \mathrm{m}$ (Fig. 3b). The fracture surface had a morphology typical of ductile fracture, with no cracks (Fig. 4). The morphology of microcracks on samples after SSRT tests in a corrosive environment is different (variants IIIV) (Fig. 5b, 7b, and 9b).

A distinct reduction in area was also observed in the specimens tested in air following prior exposure to the corrosive environment under cathodic polarization (Fig. 5a) (variant II). Moreover, on their side surfaces, there were microvoids and a large number of microcracks propagating perpendicularly to the force applied during the strain test (Fig. 5). The fracture surface (Fig. 6) had a morphology typical of ductile fracture (Fig. 6b, and d); however, there were also brittle fracture areas with numerous cracks (Fig. 6c).

The reduction in area was much smaller for the specimens tested in the corrosive environment under open-circuit potential conditions (Fig. 7a) (variant III) than for the specimens tested in air. On their side surfaces, there were corrosion pits and cracks of various lengths, propagating perpendicularly to the force applied during the strain test (Fig. 7b). Numerous microcracks of various lengths were identified on a considerable part of the fracture surfaces (Fig. 8).
The specimens strained in the corrosive environment under cathodic polarization also experienced a small reduction in area (Fig. 9a) (variant IV). There were numerous cracks and small voids on their side surfaces (Fig. 9b). A great number of cracks were identified on the fracture surface. Most cracks were several micrometers long (Fig. 10c and d), but there were also many larger cracks on the fracture surface (Fig. 10b).

A detailed analysis of the nature of the fracture of a specimen tested under cathodic polarization (variant IV) revealed that there were local intergranular areas along the edges (Fig. 11). It needs to be noted that there were also transgranular cracks in those areas.

After the WE54 specimens had undergone the SSRT tests, their fracture profiles were examined (Fig. 12). In the microstructure of the specimen tested in air (variant I), there were cracks located within the precipitates of the phases present in the alloy (Fig. 13). The crack propagation direction was perpendicular to the force applied during the strain test. The microstructure also contained voids, resulting from the plastic deformation of the alloy's matrix (Fig. 13a). The voids initiated in the areas where cracks were present or, less frequently, at the phase-matrix interphase boundaries.

The microstructure of the specimen strained in air following exposure to the corrosive environment under cathodic polarization (variant II) also had cracks in phase precipitates and voids (Fig. 14). Cracks were also identified in the matrix, by the fracture surface (Fig. 14a) and by the side surface of the specimen (Fig. 14b).

In the case of the specimens strained in the corrosive environment, both at open circuit (Fig. 15) (variant III) and under cathodic polarization (Fig. 16) (variant IV), cracks were identified in the phase precipitates present in the alloy's microstructure (Fig. 15a and 16a). However, the number of voids that accompanied them and their dimensions were much smaller in comparison with the specimens tested in air. Numerous cracks were also identified in the matrix, by the fracture surface (Fig. 15a and 16a) and by the side surface of the specimen (Fig. 15b and 16b).

\subsection{Analysis of Changes in the Mechanical Properties of the WE54 Alloy Under SCC Conditions}

The stress-strain curves obtained as a result of the SSRT tests (Fig. 2), and the results of the mechanical tests (Table 1) indicated that the WE54 alloy tested was susceptible to stress corrosion cracking in a $0.1 \mathrm{M} \mathrm{Na}_{2} \mathrm{SO}_{4}$ solution. This susceptibility was manifested in a deterioration in the plastic and strength properties, and characteristic of stress corrosion cracking (Ref 14). A similar susceptibility to stress corrosion 

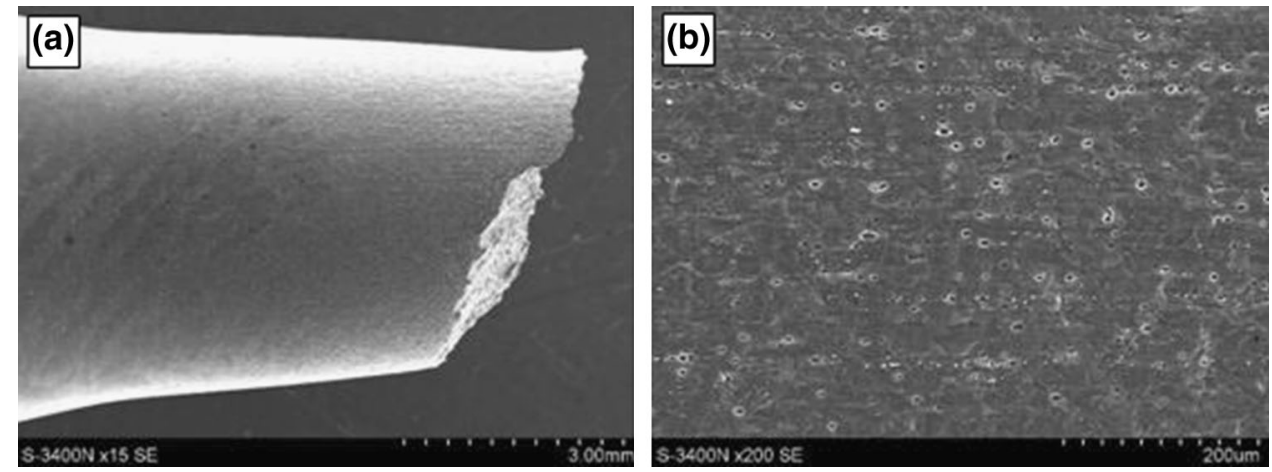

Fig. 3 Side surface of a WE54 specimen after SSRT variant 1 (strain in air): (a) macroscopic image; (b) magnification of a part of the side surface
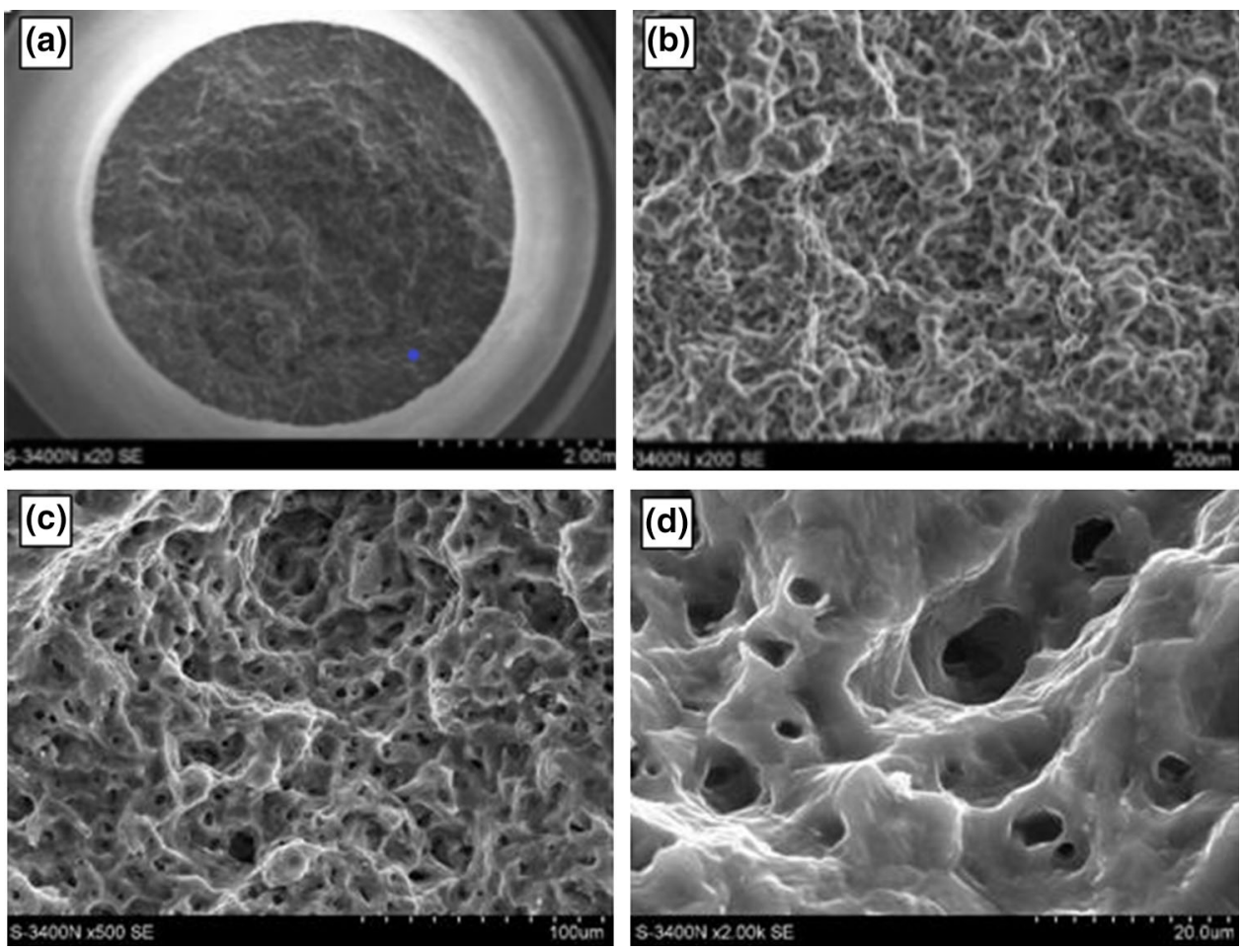

Fig. 4 WE54 fracture surface after SSRT variant 1 (strain in air): (a) macroscopic image; (b, c, d) magnifications of parts of the fracture surface, ductile fracture
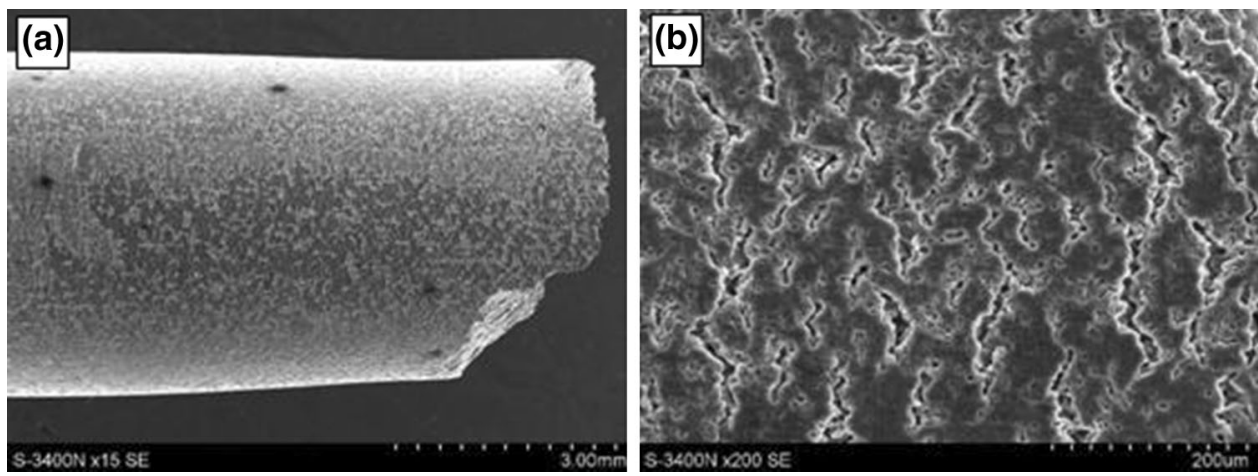

Fig. 5 Side surface of a WE54 specimen after SSRT variant 2 (strain in air following a 24-h exposure to the corrosive environment under cathodic polarization): (a) macroscopic image; (b) magnification of part of the side surface 

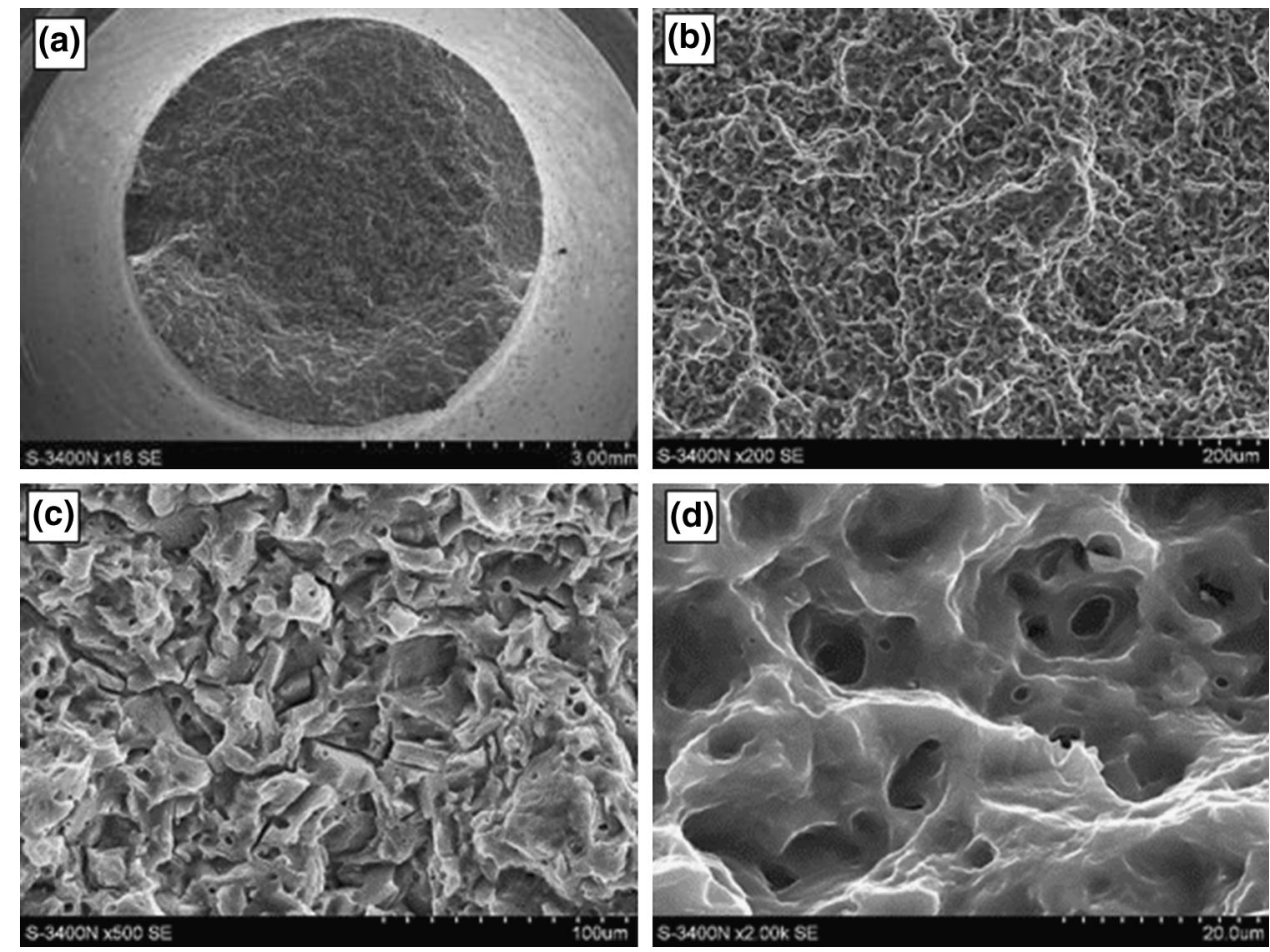

Fig. 6 WE54 fracture surface after SSRT variant 2 (strain in air following a 24-h exposure to the corrosive environment under cathodic polarization): (a) macroscopic image; (b, d) magnifications of parts of the fracture surface, ductile fracture; (c) magnification of a part of the fracture surface, brittle fracture with numerous cracks
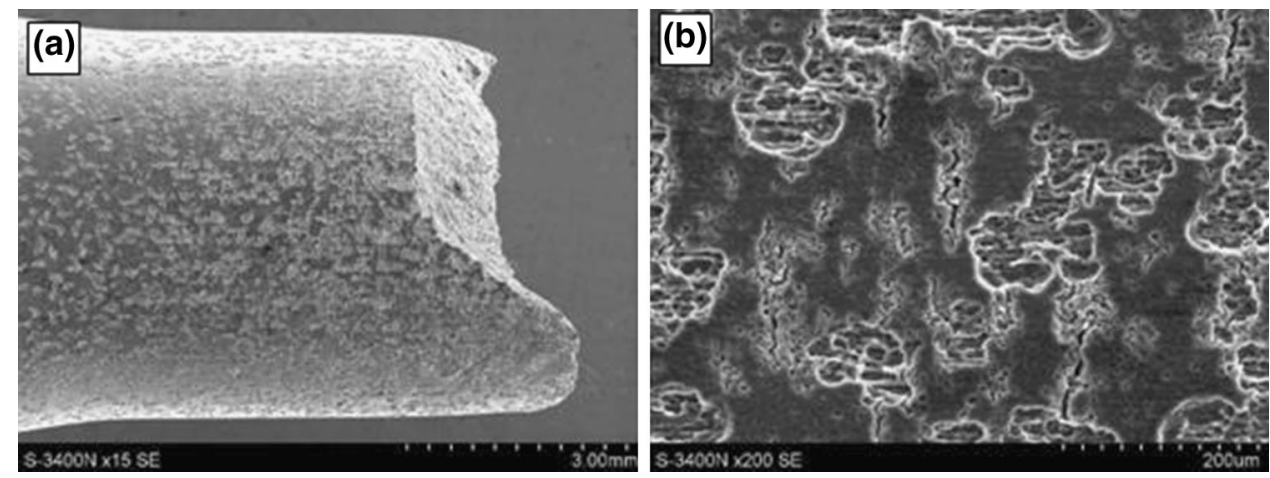

Fig. 7 Side surface of a WE54 specimen after SSRT variant 3 (strain in the corrosive environment under open-circuit potential conditions): (a) macroscopic image; (b) magnification of a part of the side surface

cracking in an environment containing $\mathrm{Na}_{2} \mathrm{SO}_{4}$ was also identified, e.g., for pure magnesium, the AZ91 and ZK60-A alloys, and Mg-Mn-Ce alloys (Ref 15-19). In order to determine the level of stress corrosion cracking susceptibility of the alloys tested, the hydrogen embrittlement index (1) was calculated for each of the specimens subjected to SSRT variants 2,3 , and 4 .

$\mathrm{HEI}_{X}=\left|\frac{X_{\text {pow }}-X_{n}}{X_{\text {pow }}}\right| \cdot 100 \%$

where $X_{\text {pow }}$-a given parameter (e.g., $\varepsilon, R_{\mathrm{m}}$ ) recorded for the specimens tested in the non-corrosive environment-air (SSRT variant I), $X_{\mathrm{n}}-$ a given parameter (e.g., $\varepsilon, R_{\mathrm{m}}$ ) recorded for the specimens tested in the corrosive environment-under SSRT variant $\mathrm{n}$ (II, III, IV).
The hydrogen embrittlement index describes (as a percentage) the change in the properties of a material resulting from strain in the corrosive environment. The change described is compared with the value of a given property recorded for strain in a non-corrosive environment-most frequently, air. In the case of the specimens described in this study, the hydrogen embrittlement index was calculated based on changes both in the plastic properties $(\varepsilon)-\mathrm{HEI}_{\varepsilon}$ and in the strength properties $\left(R_{\mathrm{m}}\right)-\mathrm{HEI}_{\mathrm{Rm}}$. The $\mathrm{HEI}_{\varepsilon}$ and $\mathrm{HEI}_{\mathrm{Rm}}$ values obtained for the specimens tested are shown in Fig. 17.

The analysis of the results obtained indicated that the exposure of WE54 to a $0.1 \mathrm{M} \mathrm{Na}_{2} \mathrm{SO}_{4}$ solution caused a major deterioration in its mechanical properties, with the plastic properties deteriorating noticeably more severely-even by $70 \div 80 \%$. The decrease in the strength properties was not so significant and reached $15 \div 20 \%$. 

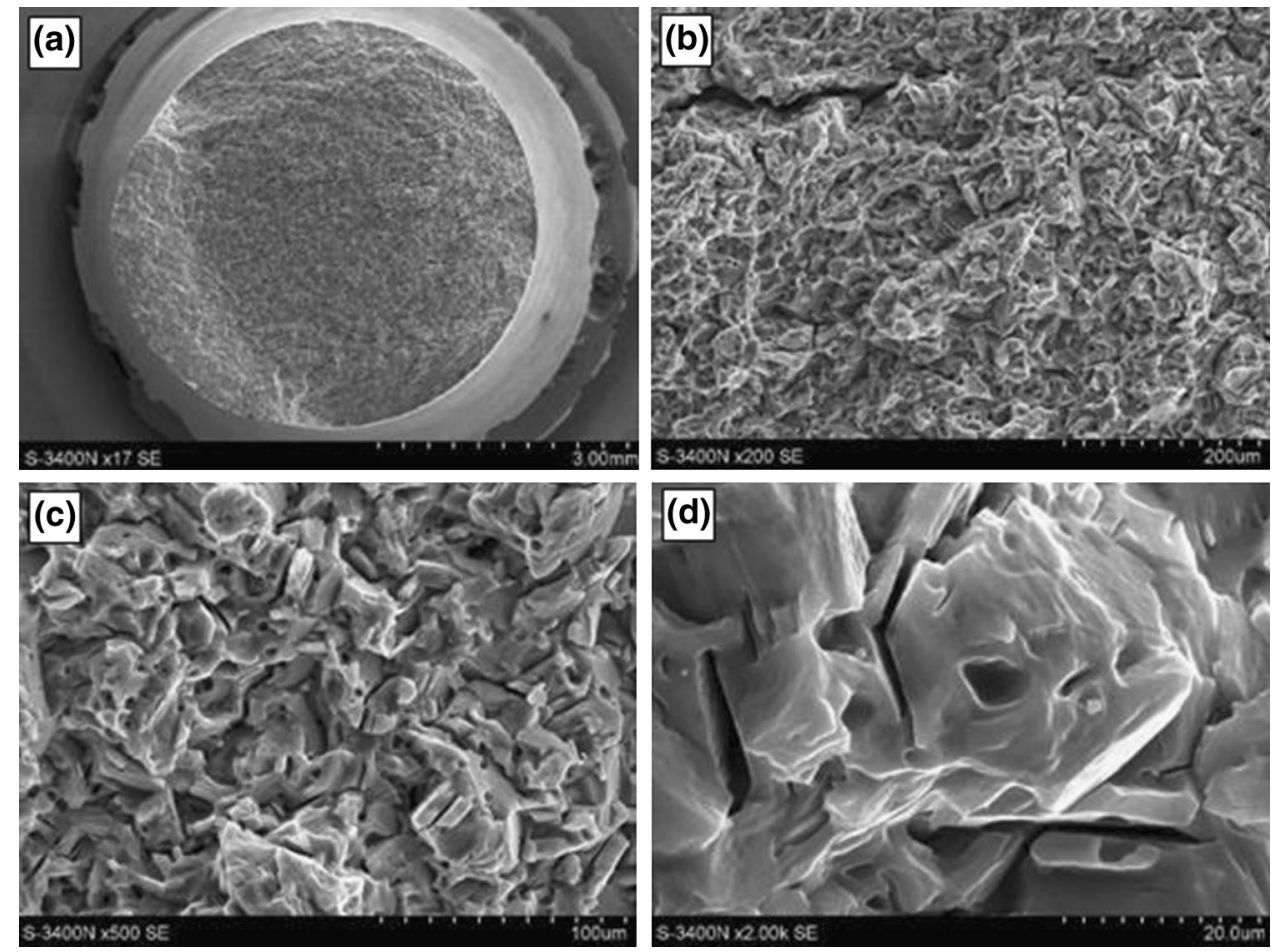

Fig. 8 WE54 fracture surface after SSRT variant 3 (strain in the corrosive environment under open-circuit potential conditions): (a) macroscopic image; (b, c, d) magnifications of parts of the fracture surface, brittle fracture with numerous cracks
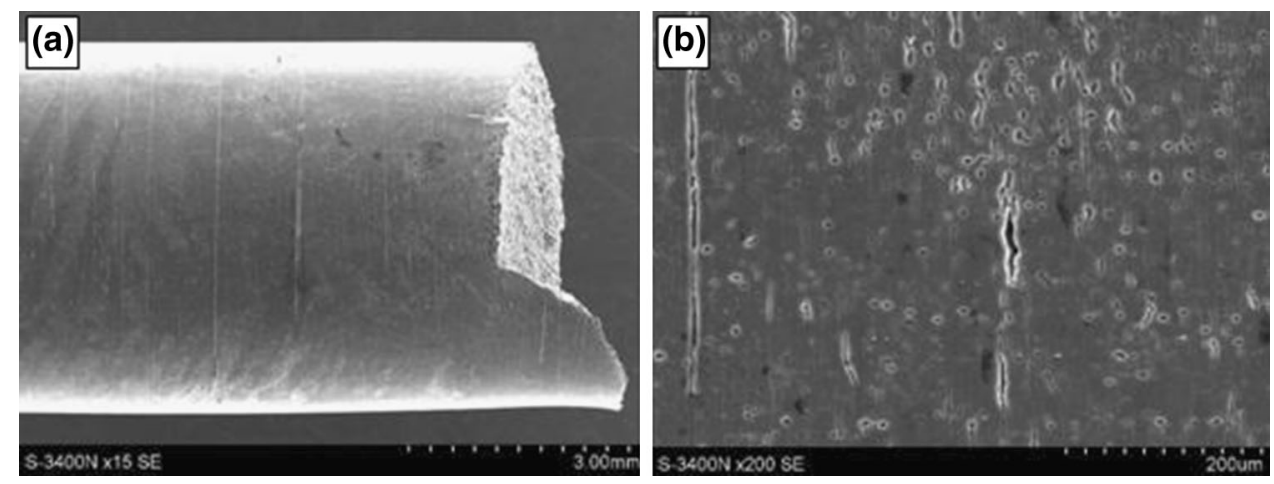

Fig. 9 Side surface of a WE54 specimen after SSRT variant 4 (strain in the corrosive environment under cathodic polarization): (a) macroscopic image; (b) magnification of a part of the side surface

The most severe deterioration in mechanical properties was observed for the specimens tested in the corrosive environment under cathodic polarization (SSRT variant IV). Under such conditions, a specimen does not corrode (due to cathodic protection), so the deterioration in its mechanical properties must result from other processes. The most probable cause is the presence of hydrogen, generated in a cathodic reaction, in the environment. Hydrogen, due to its short atomic radius, can penetrate the alloy's microstructure and travel in it relatively easily, interacting with microstructural elements being so-called hydrogen traps. The hydrogen accumulated in the microstructure leads to internal stresses and/or the formation of brittle hydride phases. The combination of stresses resulting from the interaction of hydrogen on the microstructure and external mechanical loads may lead to the initiation and growth of microcracks that may have been the cause of the deterioration in mechanical properties observed for the alloy in question.
Due to the poor protective properties of the passive layer forming on the surface of magnesium-based alloys, it does not prevent hydrogen effectively from penetrating the alloy's microstructure. Moreover, due to the strain inflicted, the layer is constantly damaged, revealing the metallic substrate and facilitating the penetration of hydrogen into the alloy.

A major deterioration in mechanical properties was also observed for the specimens tested in the corrosive environment under open-circuit potential conditions (SSRT variant III) (Fig. 2). Their elongation deteriorated by approx. $55 \div 70 \%$, whereas their tensile strength decreased by $4 \div 15 \%$. As in the case of the specimens tested under cathodic polarization, also for the specimens tested at open circuit, the cause of the deterioration in mechanical properties may have been the presence of hydrogen in the alloy's microstructure. However, in the case of the specimens tested at open circuit, the source of hydrogen was corrosion processes resulting from its exposure 

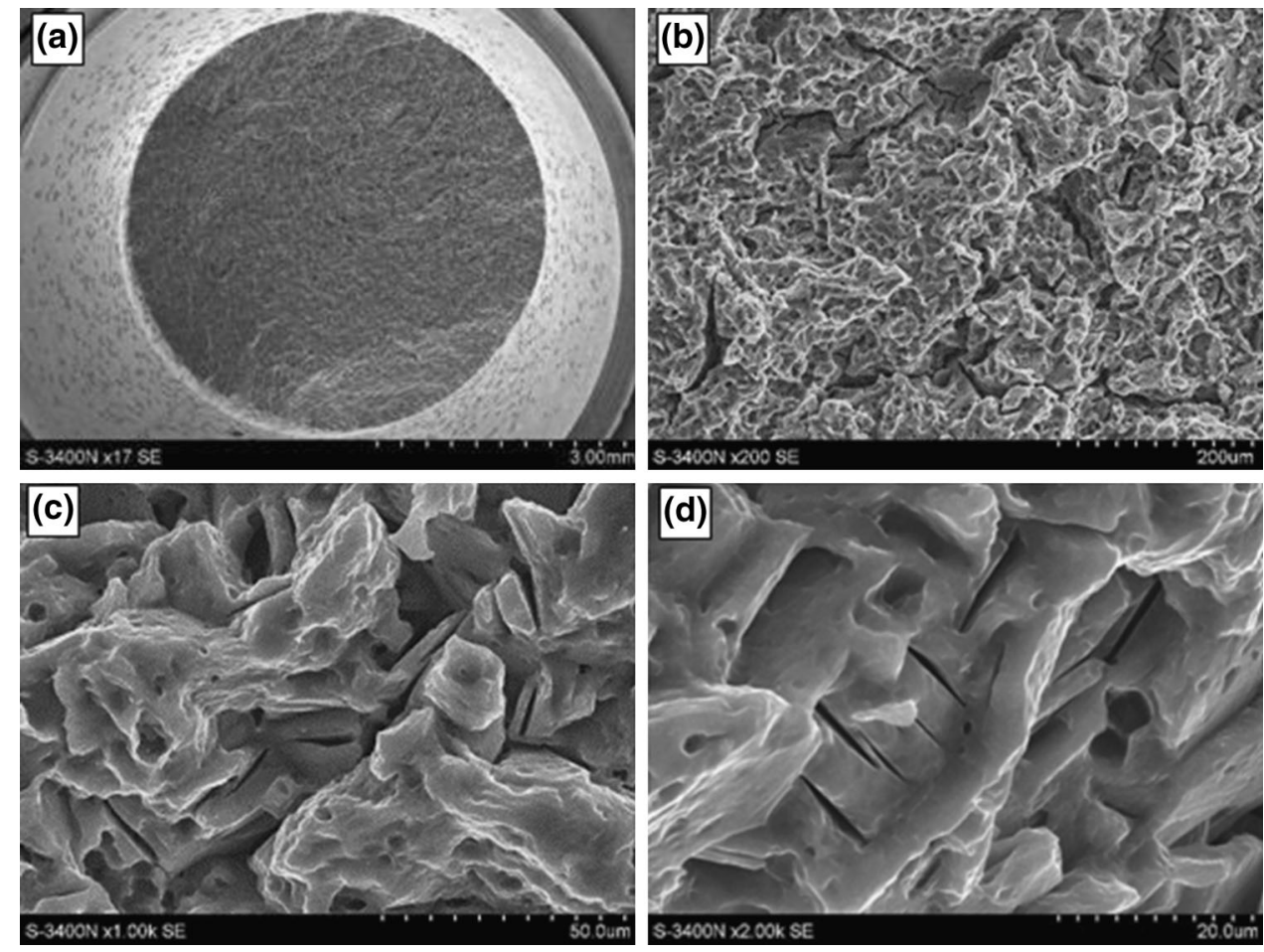

Fig. 10 WE54 fracture surface after SSRT variant 4 (strain in the corrosive environment under cathodic polarization): (a) macroscopic image; (b, c, d) magnifications of parts of the fracture surface, brittle fracture with numerous cracks
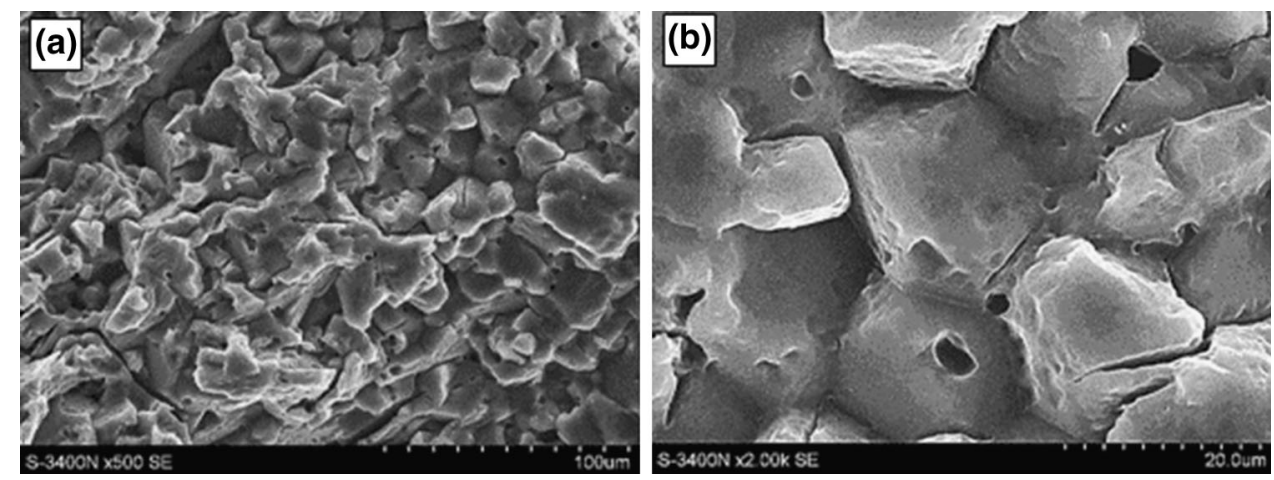

Fig. 11 WE54 fracture surface after SSRT variant 4 (strain in the corrosive environment under cathodic polarization): (a) intergranular fracture near the edge of the specimen; (b) surface morphology corresponding to the shapes of grains, characteristic of intergranular fracture

to the corrosive environment. Due to the fact that magnesiumbased alloys have poor electrochemical corrosion resistance, the intensity of corrosion processes and the quantity of hydrogen thus generated may be substantial. Moreover, the corrosion pits (Fig. 14, 15, 16) forming on the surface of the alloy act as stress concentrators and areas facilitating the penetration of hydrogen into the alloy ( $\operatorname{Ref} 8)$, thus facilitating the initiation of cracks in the alloy. Literature data inform that the worst deterioration in the mechanical properties of magnesium-based alloys is observed when they are subjected to strain in a corrosive environment under cathodic polarization, as well as under open-circuit potential conditions (Ref 20-24).

It should also be noted that the phase precipitates present in the WE54 microstructure may form galvanic microcells with the alloy's matrix. A large number of galvanic microcells generate larger quantities of hydrogen and form corrosion pits playing role of stress concentrators and facilitating the pene- tration of hydrogen. Moreover, the main components of those precipitates are magnesium, yttrium, and neodymium, which, coming into contact with hydrogen, may form hydride phases affecting adversely the alloy's properties. Literature data (Ref $25,26)$ indicate that as the concentration of these elements in magnesium-based alloys increases, the concentration of hydrogen also increases. Thus, an increased volume fraction of intermetallic phase precipitates containing rare earths may contribute both to an increased quantity of hydrogen generated in corrosion processes and an increased absorption of hydrogen by the alloy.

In the case of the specimens tested in air after prior exposure to the corrosive environment under cathodic polarization (SSRT variant II), a minor deterioration in the mechanical properties was observed (Fig. 2). In the light of this fact, it can be stated that the received values indicate a minor effect of the environment on the mechanical properties of the alloy tested, or 

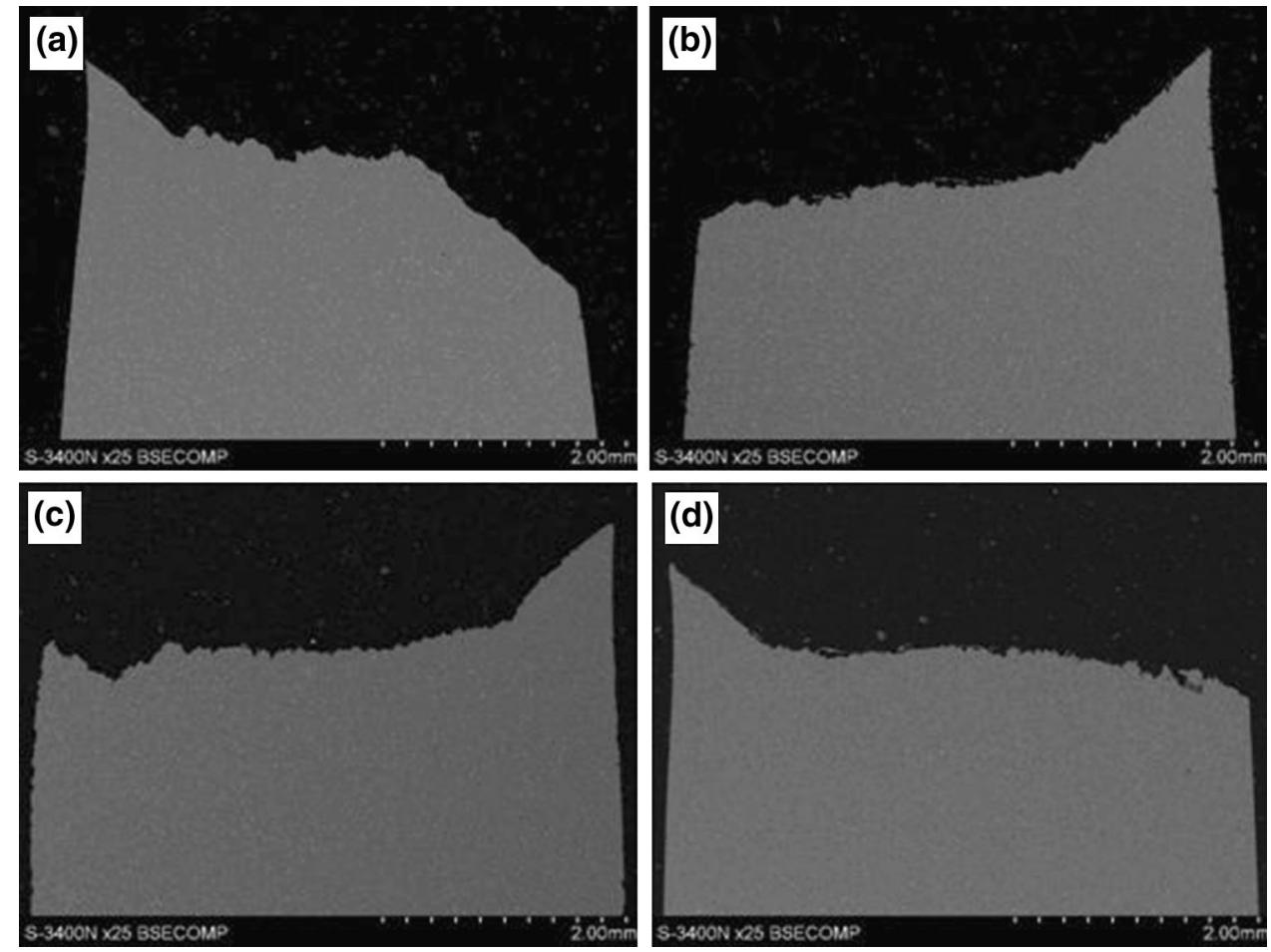

Fig. 12 WE54 fracture profile after: (a) SSRT variant 1; (b) SSRT variant 2; (c) SSRT variant 3; (d) SSRT variant 4
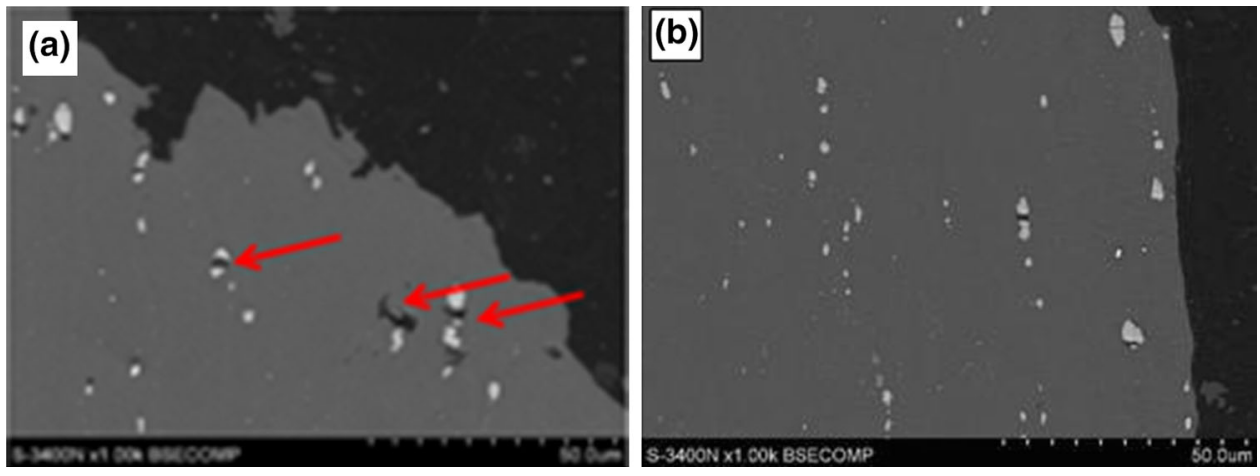

Fig. 13 WE54 fracture profile after SSRT variant 1: (a) fracture surface; (b) specimen side surface
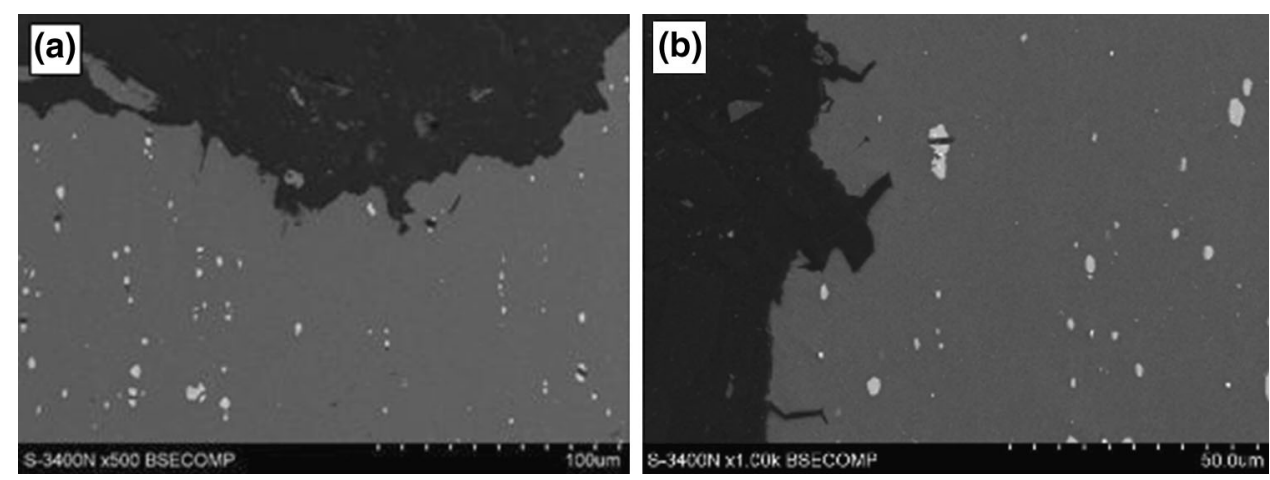

Fig. 14 WE54 fracture profile after SSRT variant 2: (a) fracture surface; (b) specimen side surface

even the absence of such effect. This may result from the absence of external mechanical loads during the exposure of the specimens tested to the corrosive environment. One of the basic roles performed by external mechanical loads is the constant damaging of the passive layer forming on the alloy surface and thus continuous revealing of the metallic substrate through 

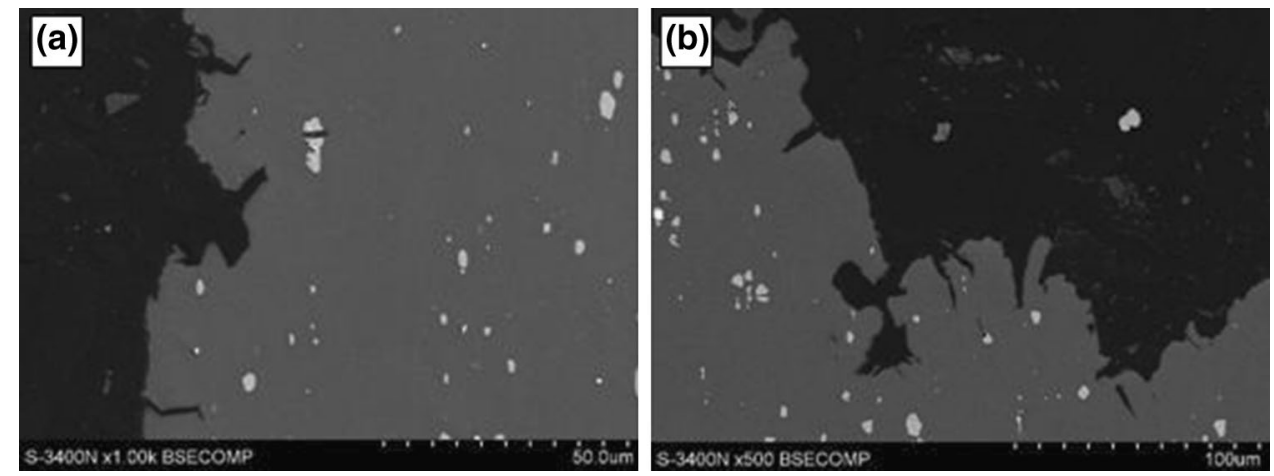

Fig. 15 WE54 fracture profile after SSRT variant 3: (a) fracture surface; (b) specimen side surface
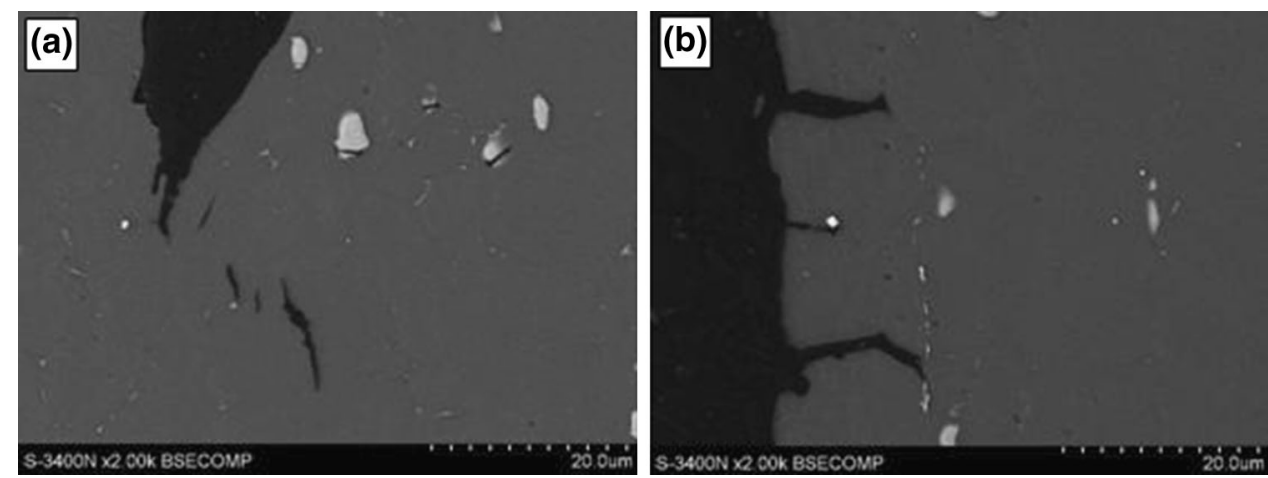

Fig. 16 WE54 fracture profile after SSRT variant 4: (a) fracture surface; (b) specimen side surface
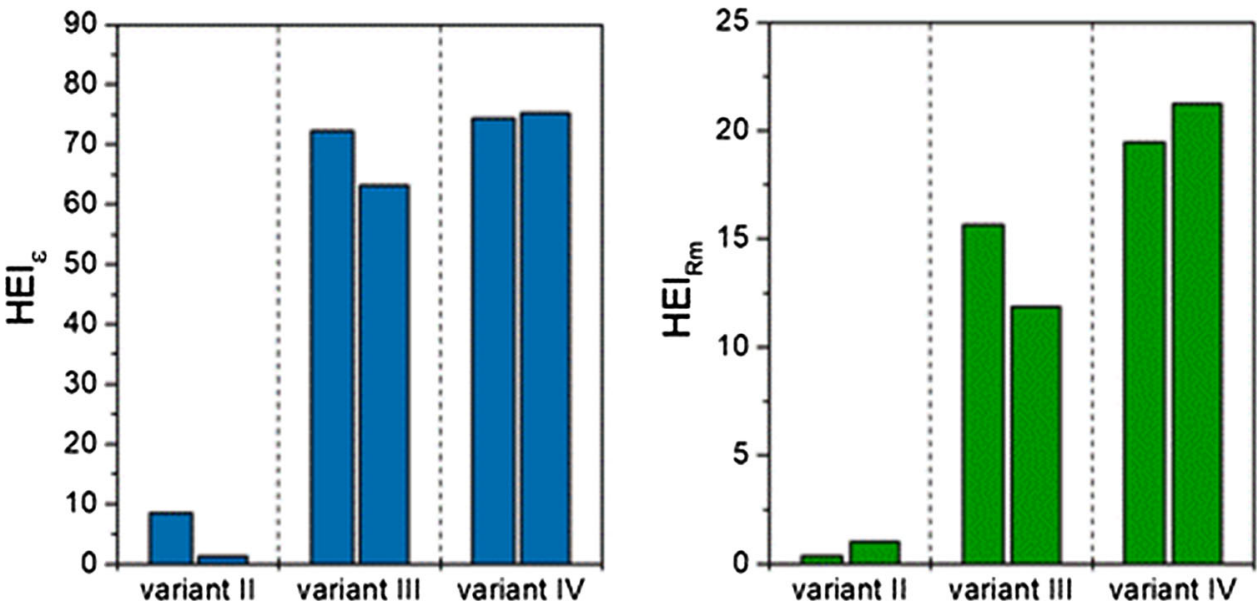

Fig. $17 \mathrm{HEI}_{\varepsilon}$ and $\mathrm{HEI}_{\mathrm{Rm}}$ calculated for the WE54 specimens subjected to SSRT variants 2, 3, and 4

which hydrogen is able to penetrate deep into the alloy more easily. In the absence of external mechanical loads, the passive layer has better protective properties and is more effective in reducing the penetration of hydrogen into the alloy's microstructure. Another major factor is hydrogen diffusivity in the crystal lattice of magnesium (Ref 7-11). The literature provides very different data in this respect; however, most frequently, authors claim it to be $10^{-12} \div 10^{-13} \mathrm{~m}^{2} / \mathrm{s}$. This being a very small value, it may be very difficult for hydrogen to diffuse at long distances in a short period of time. Thus, hydrogen penetrating the alloy should accumulate in a thin layer close to the surface, with its depth depending on the exposure time. At the same time, the presence of hydrogen in the alloy should lead to a deterioration in its properties only in the areas where it is actually present, which in the case of short exposure times is only a small fraction of a specimen's cross section and may have a negligible effect on the properties of the entire specimen. Literature data concerning the effect of preexposure of magnesium-based alloys on their mechanical properties both confirm its significant influence on deterioration in the alloys' properties (Ref 7, 20) and deny such significant influence (Ref 21). This information suggests that hydrogen diffusivity in magnesium-based alloys is sufficient for hydrogen to be able to move freely in said alloys. A more important 
factor reducing the penetration of hydrogen into an alloy appears to be the presence of a passive layer (Ref 7, 11), whose protective properties depend crucially on the chemical composition of the alloy on which it forms and on the chemical composition of the environment to which it is exposed.

An analysis of the concentration of hydrogen present in the specimens obtained as a result of the SSRT tests revealed that the specimens tested in the corrosive environment were characterized by the highest concentration of hydrogen in their volumes. The lowest hydrogen concentration, in turn, was recorded for the non-exposed specimens strained in air. An identical correlation was observed during the analysis of the hydrogen embrittlement indices $\mathrm{HEI}_{\varepsilon}$ and $\mathrm{HEI}_{\mathrm{Rm}}$, and the most severe deterioration in mechanical properties was recorded for the specimens tested in the corrosive environment under cathodic polarization (Fig. 17).

The results confirm the significant role of hydrogen in the stress corrosion cracking processes occurring in the alloy studied. Hydrogen concentration was also higher in the WE54 specimens subjected to SSRT variants II and III than in the nonexposed specimens strained in air. However, hydrogen concentration did not increase proportionately to the deterioration in the specimens' properties in the case of each of these two variants. This may result from the fact that the measurement of the actual hydrogen concentration in the specimens analyzed may be disrupted by the presence of the remains of an $\mathrm{Mg}(\mathrm{OH})_{2}$ layer, forming on the alloy surface in contact with the corrosive environment, on the surface and in the material's discontinuities (Ref 7). Moreover, the results obtained may have been affected by the prolonged, and not identical for each sample, time between the SSRT test and the hydrogen concentration analysis. Bearing in mind that the hydrogen concentrations recorded for the specimens were low, up to $50 \mathrm{ppm}$, a change in hydrogen concentration by several ppm, caused by its escape from the material or the presence of $\mathrm{Mg}(\mathrm{OH})_{2}$ in the sample tested, would significantly affect the result obtained (Fig. 18).

\subsection{Analysis of the Effects of Stress Corrosion Cracking in WE54 on the Fracture Surfaces}

The analysis of the fracture surfaces obtained as a result of the SSRT tests showed that the WE54 specimens tested in air (variant I) displayed ductile fracture (Fig. 3 and 4), with the characteristic voids and bridges forming due to the considerable

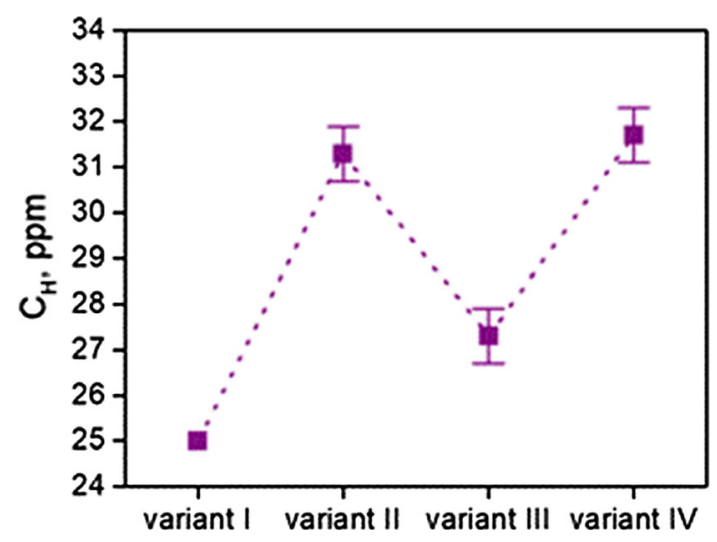

Fig. 18 Hydrogen concentration $\mathrm{C}_{\mathrm{H}}$ in WE54 specimens after SSRT variants $1,2,3$, and 4 plastic deformation. The entire fracture surfaces obtained in this test variant had a very similar morphology. No cracks were identified on the surfaces. An analysis of the side surfaces of these specimens (Fig. 3 and 5) did not reveal the presence of any cracks, either. However, voids were detected, formed in areas where phase precipitates were present as a result of the considerable plastic deformation, manifested also in the form of a clearly visible reduction in area (Fig. 3a). An analysis of the fracture profiles of the WE54 specimens obtained in the SSRT test in air (variant 1) confirmed the absence of cracks in the specimens. None were found either on the fracture surfaces (Fig. 12a, 13a and 14a) or on the specimen side surfaces (Fig. 13b, 14b and 15b). However, intermetallic phase precipitate cracks were detected in the microstructure along with the associated voids (Fig. 19).

The most likely cause of their formation is stress occurring in the alloy's microstructure during the SSRT test. This is confirmed by the direction in which the cracks were oriented, and it was perpendicular to the force applied during the strain test. This is clearly visible in Fig. 19. The voids accompanying the cracks form when fragmented phase precipitates move along with the surrounding matrix, which undergoes plastic strain. It should be noted that thus formed phase precipitate cracks have not been observed to initiate cracks in the volume of the neighboring solid solution.

The fracture surfaces of the WE54 specimens tested under the other SSRT variants (II, III, IV) (Fig. 6, 8 and 10) were characterized by the presence of both ductile fracture areas and brittle (mainly transgranular) fracture areas. In the case of the specimens tested in the corrosive environment under cathodic polarization, intergranular fracture was detected in some areas, near the edges of the fracture surfaces (Fig. 11). The literature concerning magnesium-based alloys informs that stress corrosion cracking is often indicated by the presence of transgranular brittle fracture areas on the fracture surfaces (Ref 10, 19, 21, 23, 27). Additionally, fracture surfaces of a mixed nature are often encountered with transgranular fracture areas and scarce intergranular fracture areas (Ref 7, 11). Intergranular fracture is the least frequently encountered type of fracture (Ref 28). A characteristic feature of the fracture surfaces of the specimens tested under SSRT variants II, III, and IV was the presence of secondary cracks. A particularly large number of such cracks were observed on the surfaces of the specimens tested in the corrosive environment, both at open-circuit conditions (variant

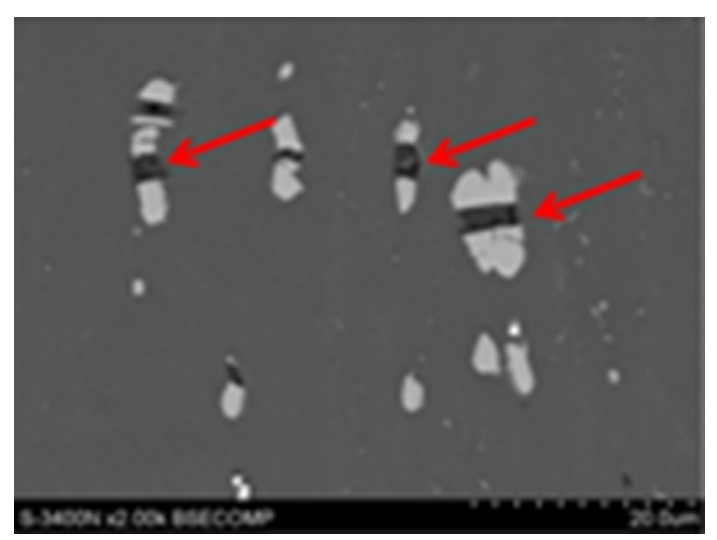

Fig. 19 Cracks of phase precipitates present in the WE54 microstructure, resulting from stresses occurring during the SSRT test 


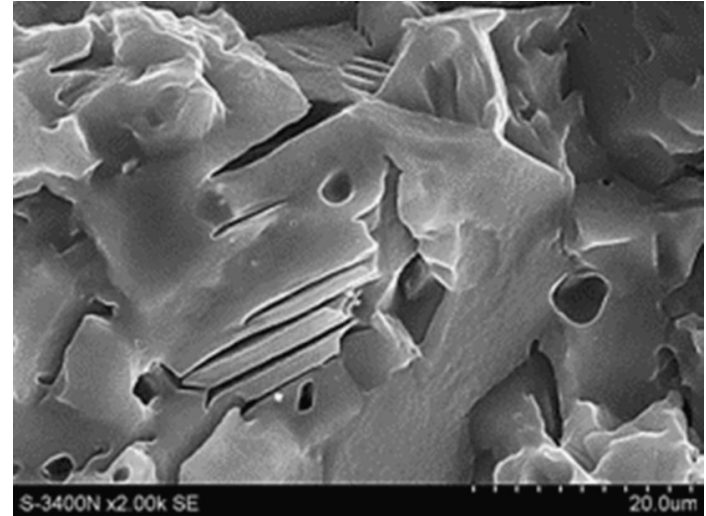

Fig. 20 Series of parallel cracks present on the fracture surfaces obtained as a result of the SSRT tests on WE54 specimens

III) and under cathodic polarization (variant IV). The great majority of those cracks were short, and their lengths were comparable to the size of a grain in the alloy. Moreover, it was observed that the cracks were often parallel to one another within small areas whose size was comparable to the size of a grain in the specimens tested (Fig. 20). This fact suggests that within a single grain, such cracks formed on parallel crystallographic planes. Cracks were also identified on the side surfaces of the specimens analyzed (Fig. 5, 7 and 9). They had various sizes and their propagation direction was perpendicular to the force applied during the strain test. Additionally, corrosion pits were identified on the side surfaces of the specimens tested during exposure to the corrosive environment under open-circuit conditions (Fig. 7).

An analysis of the fracture profiles of the WE54 specimens tested in air following exposure to the corrosive environment (variant 2) and in the corrosive environment under open-circuit conditions (variant 3) and under cathodic polarization (variant 4) also revealed the presence of cracks in the microstructure of the alloys tested (Fig. 14, 15 and 16). The cracks were located near all surfaces coming into contact with the corrosive environment, i.e., both by the fracture surfaces and by the side surfaces. The numbers and the sizes of the cracks were noticeably larger in the case of the specimens tested in the corrosive environment, both under open-circuit conditions and under cathodic polarization. However, the branched crack layouts resembling trees, propagating from the surface deep into the material and characteristic of hydrogen damage in, e.g., steel were not observed in any of the specimens. The reasons behind this are probably the low diffusivity of hydrogen in the crystal lattice of magnesium and the formation of a passive layer on the surface of the metal (Ref 8, 30-34). These two factors reduce the penetration of hydrogen deep into the alloy in such a short time as the duration of an SSRT test. Moreover, it was observed that the cracks did not always propagate from the surface of the specimen. Some cracks were located within the $\alpha-\mathrm{Mg}$ solid solution, a small distance from the surface of the specimen or in close vicinity of the tips of other cracks (Fig. 21).

This suggests that cracks present in the microstructure of the WE54 alloy may propagate both by growth in the region directly adjacent to the crack tip, where the peak tensile stresses occur, and by the coalescence of individually propagating cracks located in hydrogen-saturated areas in the alloy. Moreover, in the microstructure of the specimens tested in

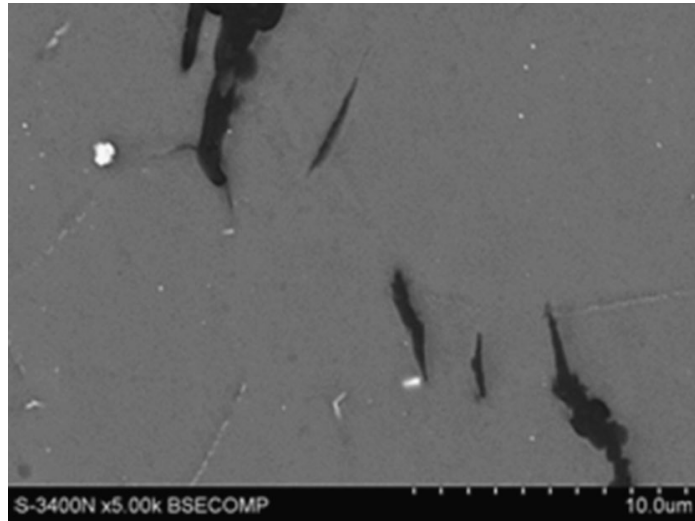

Fig. 21 Cracks present within the $\alpha$-Mg solid solution in the WE54 alloy, identified at the fracture profiles obtained as a result of the SSRT tests

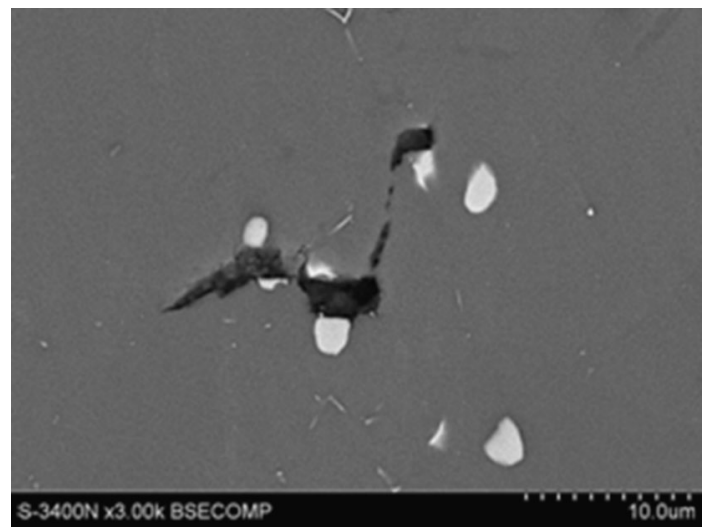

Fig. 22 Microstructure of the fracture profiles of the WE54 specimens tested during exposure to the corrosive environment; the cracking of intermetallic phase precipitates initiating the cracking of the surrounding alloy matrix

the corrosive environment, there were no voids, or there were very small voids, located in crack areas (Fig. 22). This indicates that the alloy matrix surrounding them had much worse plastic properties, which may have resulted from the presence of hydrogen in those areas. Another effect of that loss of ductility by the alloys matrix is the presence of cracks in its volume, initiated by the cracking of the intermetallic phase precipitates present in the alloy (Fig. 22). No similar effect was observed for the specimens that were not exposed to a hydrogencontaining environment. Similar effects have been observed for other magnesium alloys with rare earth elements (Ref 35 ).

\section{Conclusions}

The analysis of the results obtained led to the formulation of the following conclusions:

1. The magnesium-based alloy with rare earth elements - WE54 - shows a susceptibility to stress corrosion cracking in a $0.1 \mathrm{M} \mathrm{Na}_{2} \mathrm{SO}_{4}$ solution; its strength properties (tensile strength) and plastic properties (elongation and reduction in area) deteriorate. This results from the 
degradation of their microstructure (the initiation and growth of microcracks) caused by the presence of hydrogen.

2. The specimens tested in air following exposure to the corrosive environment under cathodic polarization had mechanical properties (tensile strength, yield, elongation, reduction in area) very similar to the properties recorded for the WE54 alloy in the initial condition.

3. The highest hydrogen concentration was recorded for the specimens tested under cathodic polarization $\left(C_{\mathrm{H}}=31.7\right.$ $\pm 0.6 \mathrm{ppm})$ and the specimens tested in air following exposure under cathodic polarization $\left(C_{\mathrm{H}}=31.3 \pm 0.6\right.$ $\mathrm{ppm})$. The specimens tested under open-circuit conditions had a medium hydrogen concentration $\left(C_{\mathrm{H}}=27.3 \pm 0.6\right.$ $\mathrm{ppm})$. The hydrogen concentration in the specimens tested in air was $C_{\mathrm{H}}=25.0 \pm 0.0 \mathrm{ppm}$.

4. The most severe deterioration in the strength and plastic properties of the WE54 alloy occurred as a result of strain during exposure to an $\mathrm{Na}_{2} \mathrm{SO}_{4}$ solution under cathodic polarization. Such conditions ensure the constant generation of large quantities of hydrogen into the hydrogen charging solution and the continuous damaging of the passive layer that forms on the surface of the alloy. The presence of this layer limits the penetration of hydrogen into the alloy, but damage to the layer increases the penetration of hydrogen into the microstructure.

5. The analysis of the morphology of the fracture surfaces and the fracture profiles revealed that:

- there were no cracks on the fracture surfaces of the specimens tested in air, and the fracture was ductile in nature;

- brittle fracture areas and microcracks were identified on the fracture surfaces of the specimens tested following or during exposure to the corrosive environment, and the largest numbers of such areas and microcracks were present on the fracture surfaces of the specimens tested during exposure to the corrosive environment;

- the microcracks present on the fracture surfaces were mostly transgranular in nature, and intergranular cracks were rare;

- secondary cracks present on the fracture surfaces were small sized and were located only in the close vicinity of the fracture surfaces.

\section{Acknowledgments}

This work was supported by the National Science Centre in Poland under the research grant "Effect of hydrogen on structure and stress corrosion cracking of selected magnesium alloys from Mg-Y-RE-Zr and Mg-Al-RE systems" No. 2011/03/B/ST8/06387.

\section{Data Availability}

The raw/processed data required to reproduce these findings cannot be shared at this time as the data also form part of an ongoing study.

\section{Open Access}

This article is licensed under a Creative Commons Attribution 4.0 International License, which permits use, sharing, adaptation, distribution and reproduction in any medium or format, as long as you give appropriate credit to the original author(s) and the source, provide a link to the Creative Commons licence, and indicate if changes were made. The images or other third party material in this article are included in the article's Creative Commons licence, unless indicated otherwise in a credit line to the material. If material is not included in the article's Creative Commons licence and your intended use is not permitted by statutory regulation or exceeds the permitted use, you will need to obtain permission directly from the copyright holder. To view a copy of this licence, visit http://creativecommons.org/licenses/by/4.0/.

\section{References}

1. H.E. Friedrich and B.L. Mordike, Magnesium Technology: Metallurgy, Design Data, Applications, Springer, Berlin, 2006, p 145-218

2. T. Rzychoń and A. Kiełbus, Microstructure of WE43 Casting Magnesium Alloy, J. Achiev. Mater. Manuf. Eng., 2007, 21(1), p 31-34

3. M.K. Kulekci, Magnesium and Its Alloys Applications in Automotive Industry, Int. J. Adv. Manuf. Technol., 2008, 39, p 851-865

4. B. Janik, The Use of Magnesium Alloys in Aviation (Zastosowanie stopów magnezu w lotnictwie), Works of the Institute of Aviation, 2011, 221, p 102-108 (in Polish)

5. W.A. Monteiro, S.J. Buso, and L.V. da Silva, Application of Magnesium Alloys in Transport, in: W.A. Monteiro (Ed.), New Features on Magnesium Alloys, InTech, 2012, p 1-14

6. M. Sozańska, Hydrogen-assisted environmental degradation. Theoretical and practical issues. Publisher of the Silesian University of Technology (Niszczenie środowiskowe wspomagane wodorem. Zagadnienia teoretyczne i praktyczne, Wydawnictwo Politechniki Śląskiej), Gliwice, 2017 (in Polish)

7. R.G. Song, C. Blawert, W. Dietzel, and A. Atrens, A Study on Stress Corrosion Cracking and Hydrogen Embrittlement of AZ31 Magnesium Alloy, Mat. Sci. Eng. A-Struct., 2005, 399, p 308-317

8. A. Atrens, N. Winzer, G. Song, W. Dietzel, and C. Blawert, Stress Corrosion Cracking and Hydrogen Diffusion in Magnesium, Adv. Eng. Mater., 2006, 8, p 749-751

9. N. Winzer, A. Atrens, G. Song, E. Ghali, W. Dietzel, K.U. Kainer, N. Hort, and C. Blawert, A Critical Review of the Stress Corrosion Cracking (SCC) of Magnesium Alloys, Adv. Eng. Mater, 2005, 8, p 659-693

10. N. Winzer, A. Atrens, W. Dietzel, V.S. Raja, G. Song, and K.U. Kainer, Characterisation of Stress Corrosion Cracking (SCC) of Mg-Al Alloys, Mat. Sci. Eng. A-Struct., 2008, 488, p 339-351

11. J. Chen, J. Wang, E. Han, J. Dong, and W. Ke, States and Transport of Hydrogen in the Corrosion Process of an AZ91 Magnesium Alloy in Aqueous Solution, Corros. Sci., 2008, 50, p 1292-1305

12. M. Henthorne, The Slow Strain Rate Stress Corrosion Cracking Test-a 50 Year Retrospective, Corrosion, 2016, 72(12), p 1488-1518

13. S. Kocańda, Fatigue Destruction of Metals (Zmęczeniowe niszczenie metali), WNT, Warszawa, 1978 (in Polish)

14. Report on the Project of National Science Centre in Poland Under the Research Grant. Effect of Hydrogen on Structure and Stress Corrosion Cracking of Selected Magnesium Alloys from Mg-Y-RE-Zr and MgAl-RE Systems. No. 2011/03/B/ST8/06387

15. J. Wang, J. Chen, E. Han, and W. Ke, Investigation of Stress Corrosion Cracking Behaviors of an AZ91 Magnesium Alloy in $0.1 \mathrm{kmol} / \mathrm{m}^{3}$ $\mathrm{Na}_{2} \mathrm{SO}_{4}$ Solution Using Slow Strain Rate Test, Mater. Trans., 2008, 49(5), p 1052-1056

16. R.S. Stampella, R.P.M. Procter, and V. Ashworth, Environmentallyinduced cracking of magnesium, Corros. Sci., 1984, 4, p 325-334

17. N.D. Tomashov and V. Modestova, in: I.A. Levin (Ed.), Intercrystalline Corrosion and Corrosion of Metals Under Stress, London, 1962 
18. M. Speidel, M.J. Blackburn, T. Beck and J.A. Feeney, Corrosion Fatigue: Chemistry, Mech. Microstruct., NACE-2, 324, p 1972

19. J. Chen, J. Wang, E. Han, and W. Ke, Effect of Hydrogen on Stress Corrosion Cracking of Magnesium Alloy in $0.1 \mathrm{M} \mathrm{Na}_{2} \mathrm{SO}_{4}$ Solution, Mater. Sci. Eng. A, 2008, 488(1-2), p 428-434

20. L.F. Zhou, Z.Y. Liu, W. Wu, X.G. Li, C.W. Du, and B. Jiang, Stress Corrosion Cracking Behavior of ZK60 Magnesium Alloy Under Different Conditions, Int. J. Hydrog. Energy, 2017, 42, p 26162 26174

21. M. Bobby Kannan, W. Dietzel, R.K.S. Raman, and P. Lyon, HydrogenInduced-Cracking in Magnesium Alloy Under Cathodic Polarization, Scripta Materialia, 2007, 57, p 579-581

22. L. Choudhary, R.K. Singh Raman, J. Hofstetter, and P.J. Uggowitzer, In-Vitro Characterization of Stress Corrosion Cracking of AluminiumFree Magnesium Alloys for Temporary Bio-Implant Applications, Mater. Sci. Eng. C, 2014, 42, p 629-636

23. S.D. Wang, D.K. Xu, B.J. Wang, L.Y. Sheng, E.H. Han, and C. Dong, Effect of Solution Treatment on Stress Corrosion Cracking Behavior of an as-Forged Mg-Zn-Y-Zr Alloy, Sci. Rep., 2016, 6, p 1-12

24. L. Choudhary and R.K. Singh Raman, Magnesium Alloys as Body Implants: Fracture Mechanism Under Dynamic and Static Loadings in a Physiological Environment, Acta Biomaterialia, 2012, 8(2), p 916 923

25. E.F. Volkova and G.I. Morozova, Role of Hydrogen in Deformed Magnesium Alloys of the Mg-Zn-Zr-REM System, Met. Sci. Heat Treatment, 2008, 50, p 105-109

26. X. Liu, S. Yin, Q. Lan, J. Xue, Q. Le, and Z. Zhang, Investigation of the Hydrogen States in Magnesium Alloys and Their Effects on Mechanical Properties, Mater. Des., 2017, 134, p 446-454

27. J. Chen, M. Ai, J. Wang, E.H. Han, and W. Ke, Stress Corrosion Cracking Behaviors of AZ91 Magnesium Alloy in Deicer Solutions Using Constant Load, Mater. Sci. Eng. A, 2009, 515, p 79-84
28. M. Bobby Kannan, W. Dietzel, C. Blawert, A. Atrens, and P. Lyon, Stress Corrosion Cracking of Rare-Earth Containing Magnesium Alloys ZE41, QE22 and Elektron 21 (EV31A) Compared with AZ80, Mater. Sci. Eng. A, 2008, 480(1-2), p 529-539

29. ASTM G129-00 (2013): Standard Practice for Slow Strain Rate Testing to Evaluate the Susceptibility of Metallic Materials to Environmentally Assisted Cracking

30. P. Spatz, H.A. Aebischer, A. Krozer, and L. Schlapbach, The Diffusion of $\mathrm{H}$ in $\mathrm{Mg}$ and the Nucleation and Growth of $\mathrm{MgH}_{2}$ In Thin Films, Zeitschrift Fur Physikalische Chemie, 1993, 181, p 393397

31. V. Knotek, V. Hošek, D. Vojtěch, P. Novák, J. Šerák, A. Michalcová, F. Průša, T. Popela, and M. Novák, Properties Of Magnesium Alloys For Hydrogen Storage, Proceedings of the 19th International Conference on Metallurgy and Materials, 2010, 1-6

32. G. Makar, J. Kruger, and K. Sieradzki, Stress Corrosion Cracking of Rapidly Solidified Magnesium-Aluminum Alloys, Corros. Sci., 1993, 34(8), p 1311-1342

33. W. Dietzel, M. Pfuff, and N. Winzer, Testing and Mesoscale Modelling of Hydrogen Assisted Cracking of Magnesium, Eng. Fract. Mech., 2010, 77(2), p 257-263

34. A. Gajek, I. Flis-Kabulska, T. Zakroczymski, C.-H. Yang, J.-K. Chang, and W.-T. Tsai, Study of Hydrogen Diffusion in Magnesium by the Electrochemical Permeation Method, Ochrona Przed Korozją, 2010, 11, p 513-516

35. M. Sozańska, A. Mościcki, and B. Chmiela, Investigation of Stress Corrosion Cracking in Magnesium Alloys by Quantitative Fractography Methods, Arch. Metall. Mater., 2017, 62(2), p 557-562

Publisher's Note Springer Nature remains neutral with regard to jurisdictional claims in published maps and institutional affiliations. 